\title{
Developing Business Acumen in Practice Management During Pain Fellowship: A Pain Fellow's Perspective
}

\section{TO THE EDITOR:}

I read with great interest the article by Przkora et al on "Do Pain Medicine Fellowships Provide Education in Practice Management? A Survey of Pain Medicine Fellowship Programs" (1). As a current Pain Medicine fellow who is actively in the process of searching for a job, this article really hit home for me and I wanted to commend the authors for bringing to light a topic that unfortunately has not for a multitude of reasons been given its due priority.

Like most of my co-fellows, I unfortunately never had a good grasp of "the business world." I finished high school, then off the college for a major in Biology and a minor in Psychology, with a focus on pre-medical courses. Then came medical school and another four years of anesthesiology residency, and now finally a year of pain medicine fellowship. As the authors mentioned, the majority of fellows will end up in private practice and most, including myself, are ill-equipped with the necessary business acumen to become successful outside of the clinic and procedural rooms. The entirety of my twenties was spent studying for tests and boards and learning what it is to become a proficient and safe physician. Now, as I am in the process of trying to tease out the good jobs from the not so good opportunities, that lack of business savvy really makes the search even more challenging.

Now, I also understand these issues from my training program and Program Director's point of view. They have one year to teach their fellows, many who come from different specialties, an entirely new subspecialty in pain management, and the procedural skills and fundamental concepts that come along with pain medicine. The "why" and "how" of many of the fellows' questions as they embark on their fellowship can usually only be taught and learned from didactics and reading of textbooks. This takes up the little non-clinical time they have at their disposal to accomplish this daunting task. I consider myself extremely fortunate to have matched at a program where we receive daily didactics taught every morning by our attendings. This imparting of knowledge is something I do not take for granted and it is something I look forward to each day. Similar to the results obtained by the authors in their survey, I would say our program fits into the 1-4 hours of formal education in the 9 specific categories of practice management education.

As for solutions to this issue, although I do agree that a mandate for formal education in practice management for fellows be implemented and covered twice in the course of the year, I do not know if there is enough of that precious non-clinical time to be allocated to this. In this regard, emerging question and answer databases and study articles such as Scientific American Pain Section (2) can supplement our education and leave additional time for practice management education, as can focused practice management courses put out by organizations such as the American Society of Interventional Pain Physicians. Another possibility could be the implementation of a day long or weekend long fellows only practice management didactics and breakout small groups session at all of the national or regional pain medicine meetings. Although this may be difficult to create, if one basic course that consists of several hours over one to two days is created and installed as part of a regional or national pain conference, this could afford an opportunity for fellows to have access to this valuable information and knowledge and then would circumvent the issue of valuable didactic time, which can be continued to be spent on the procedural and foundational concepts of pain medicine.

\author{
Omar Viswanath, MD \\ Department of Anesthesiology, Critical Care, \\ and Pain Medicine \\ Beth Israel Deaconess Medical Center \\ 330 Brookline Ave, Rabb-239 \\ Boston, MA 02215 \\ E-mail: oviswana@bidmc.harvard.edu
}




\section{References}

1. Przkora R, Antony A, McNeil A, Brenner G], Mesrobian J, Rosenquist R, Abouleish AE. Do Pain Medicine Fellowship Programs Provide Education in Practice
Management? A Survey of Pain Medicine Fellowship Programs. Pain Physician 2018; 21:E43-E48.
2. Scientific American Pain Management. https://www.deckerip.com/products/scientific-american-pain-management/

\section{In Response to Comments and Concerns from Dr. Viswanath}

We appreciate Dr. Viswanath's the input and comments (1). His viewpoint reinforces the vital importance of practice management education during fellowship training in pain medicine. We agree that practice management lectures should be included in national and regional meetings and can serve as a meaningful complement to the trainee's education. Currently, the American Society of Interventional Pain Physicians Annual Meeting (ASIPP), the Practice Management Meeting of the American Society of Anesthesiologists and the American Society of Regional Anesthesia and Pain Medicine Annual Meetings have all expanded the content addressing the practice and business management aspects for all providers, including those in training $(2,3)$. Various state societies have made notable modifications to their annual meeting agendas as well, mainly targeted to fellows. In addition, the websites of our pain societies provide a growing amount of information relevant to practice and business management. Although these are excellent scenarios for discussion and sharing knowledge, attendance by all fellows at these meetings may be remarkably challenging, and the level of interaction and mentorship is not optimal. Hence, our recommendation that practice and business management education should primarily take place inside the fellowship programs, e.g., twice a year, free of industry bias, with active participation of each one of the current fellows, and promoting valuable mentorship and follow-up of acquired knowledge and skills. In this setting, development of a formal curriculum, including the 9 topics mentioned in our discussion, 1 might provide more uniformity and inclusiveness.
Additional learning tools, suggested for supplementation and to leave additional time for practice management education, should be used at the discretion of every program director. They may be a viable option to be explored given the scant availability of didactic time during the one-year training period.

Rene Przkora, MD PhD
Associate Professor
Chief, Pain Medicine Division
Program Director
Multidisciplinary Pain Medicine Fellowship
Assistant Program Director
Anesthesiology Residency
Department of Anesthesiology
University of Florida
College of Medicine
Gainesville, FL 32610-0254
E-mail RPrzkora@anest.ufl.edu
Juan Mora, MD
Pain Medicine Fellow
Dept. of Anesthesiology
University of Florida
Gainesville, FL 32610-0254
Adejuyigbe Adaralegbe, MD
Resident
Dept. of Anesthesiology
University of Florida
Gainesville, FL 32610-0254

\section{References}

1. Przkora R, Antony A, McNeil A, Brenner G), Mesrobian J, Rosenquist R, Abouleish AE. Do pain medicine fellowship programs provide education in practice management? A survey of pain medi- cine fellowship programs. Pain Physician 2018;21:E43-E48.

2. ASIPP annual meeting brochure: www. asipp.org/2018AnnualMeeting/o318-An-
nualMeeting-brochure.pdf

3. Practice Management meeting. Available at https://www.asahq.org/practicemanagement. Accessed 02-2018 